AperTO - Archivio Istituzionale Open Access dell'Università di Torino

\title{
A 10,000 yr record of high-resolution Paleosecular Variation from a flowstone of Rio Martino Cave, Northwestern Alps, Italy
}

\section{This is the author's manuscript}

Original Citation:

Availability:

This version is available http://hdl.handle.net/2318/1657670

since 2018-06-25T09:53:18Z

Published version:

DOI:10.1016/j.epsl.2017.12.047

Terms of use:

Open Access

Anyone can freely access the full text of works made available as "Open Access". Works made available under a Creative Commons license can be used according to the terms and conditions of said license. Use of all other works requires consent of the right holder (author or publisher) if not exempted from copyright protection by the applicable law. 
Elena Zanella ${ }^{1}$, Evdokia Tema ${ }^{1}$, Luca Lanci ${ }^{2}$, Eleonora Regattieri ${ }^{3,4}$, Ilaria Isola ${ }^{5}$, John C. Hellstrom ${ }^{6}$, Emanuele Costa ${ }^{1}$, Giovanni Zanchetta $^{5,7}$, Russell N. Drysdale ${ }^{8,9}$, Federico Magrì ${ }^{10}$

${ }^{1}$ Dipartimento di Scienze della Terra, Via Valperga Caluso 35, 10125 Torino, Italy

${ }^{2}$ Dipartimento di Scienze Pure e Applicate, Piazza della Repubblica 13, 61029 Urbino, Italy

8

${ }^{3}$ Institute of Geology and Mineralogy, University of Cologne, Zülpicher Str. 49a, 50674 Cologne, Germany

${ }^{4}$ Istituto di Geoscienze e Georisorse IGG-CNR, via Moruzzi 1, 56100 Pisa, Italy

${ }^{5}$ Istituto Nazionale di Geofisica e Vulcanologia INGV, Via della Faggiola 32, 56126 Pisa, Italy

${ }^{6}$ School of Earth Sciences, University of Melbourne, Victoria 3010 Australia

${ }^{7}$ Dipartimento di Scienze della Terra, Via S. Maria 5356126 Pisa, Italy

${ }^{8}$ School of Geography, University of Melbourne, Victoria 3010, Australia

${ }^{9}$ EDYTEM, UMR CNRS 5204, Université de Savoie-Mont Blanc, 73376 Le Bourget du Lac cedex, France

${ }^{10}$ Gruppo Speleologico Valli Pinerolesi GSVP, Club Alpino Italiano, Pinerolo, Italy

\section{Abstract}

Speleothems are potentially excellent archives of the Earth's magnetic field, capable of recording its past variations. Their characteristics, such as the continuity of the record, the possibility to be easily dated, the almost instantaneous remanence acquisition and the high time -resolution make them potentially unique high-quality Paleosecular Variation (PSV) recorders. Nevertheless, speleothems are commonly characterized by low magnetic intensities, which often limits their resolution. Here we present a paleomagnetic study performed on two cores from a flowstone from the Rio Martino Cave (Western Alps, Italy). U/Th dating indicates that the flowstone's 
deposition covers almost the entire Holocene, spanning the period ca. 0.5-9.0 ka, while an estimation of its mean growth rate is around $1 \mathrm{~mm}$ per 15 years. The flowstone is composed of columnar calcite, characterized by a highly magnetic detrital content from meta-ophiolites in the cave's catchment. This favourable geological context results in an intense magnetic signal that permits the preparation and measurement of thin $(\sim 3 \mathrm{~mm}$ depth equivalent) samples, each representing around $45 \mathrm{yr}$. The Characteristic Remanent Magnetization (ChRM), isolated after systematic stepwise Alternating Field demagnetization, is well defined, with Maximum Angular Deviation (MAD) generally lower than $10^{\circ}$. Paleomagnetic directional data allow the reconstruction of the PSV path during the Holocene for the area. Comparison of the new data with archeomagnetic data from Italian archeological and volcanic records and using the predictions of the SHA.DIF.14k and pfm9k.1a global geomagnetic field models shows that the Rio Martino flowstone represents an excellent recorder of the Earth's magnetic field during the last 9,000 years. Our high resolution paleomagnetic record, anchored by a high-quality chronology, provide promising data both for the detection of short term geomagnetic field variations and for complementing existing regional PSV curves for the prehistoric period, for which well-dated data are still scarce.

\section{Keywords: Paleosecular variation, Rock magnetism, Speleothem, Italy}

\section{Introduction}

To investigate geomagnetic field behavior in the past and to explore its short-term features, highresolution records from globally distributed archives of different origin are necessary (Mandea and Olson, 2009). For Paleosecular Variation (PSV) reconstructions, an ideal paleomagnetic record 
should satisfy several requirements, such as having a stable remanent magnetization, being well dated, offering a continuous record and presenting high-time resolution. Even though some Earth materials may satisfy a number of these, the characteristics of continuity and high-resolution are rarely coupled. Marine and lacustrine sediment sequences are best at ensuring continuous records and have therefore been intensively studied to obtain geomagnetic data over long time scales (e.g. Turner and Thompson, 1981; Rolph et al., 2004; Vigliotti, 2006). However, sometimes data reliability may be questionable: the remanence acquisition mechanisms, the smoothing effects of bioturbation, the inclination error and the remanence acquisition delay are just some of the problems that may affect this kind of record. On the other hand, volcanic rocks and fired archeological artifacts may preserve very reliable paleomagnetic data but they are highly discontinuous in time. The age uncertainties of the volcanic products, as well as the lack of continuity and the limited time extension of available in situ archeological baked clay structures, restrict their use for high-resolution record studies.

Several research groups have studied speleothems for both PSV and paleoenvironmental reconstructions (e.g. Latham et al., 1989; Lean et al., 1995; Openshaw et al., 1997; Osete et al., 2012; Xie et al., 2013; Font et al., 2014; Jaqueto et al., 2016; Lascu et al., 2016), revealing their high potential for magnetic and secular variation reconstructions (Lascu and Feinberg, 2011). Paleomagnetic time series from speleothems, although still sparse, can provide excellent temporal resolution if the speleothem has grown continuously and over a considerable age range, as, for example, in the case of the Mexican stalagmite studied in the pioneering work of Latham et al. (1986). The key features of speleothems are that they can grow continuously for $10^{3}-10^{5} \mathrm{yr}$ and can be accurately dated by the uranium-series method (e.g. Richards and Dorale, 2003). They normally show little or no secondary alteration, and are generally easy to orient and sample (though with obvious consideration of natural heritage values). 
Based on magnetic properties, the remanent magnetization of speleothems can be divided into two main genetic forms, detrital (DRM) or chemical (CRM) (Lascu and Feinberg, 2011). Detrital input can originate from flood or drip water sources (Openshaw et al., 1997; Fairchild et al., 2006). Moreover, speleothems present the advantage of acquiring their magnetization rapidly after formation, meaning that the registered magnetic remanence variations reliably reflect the PSV path in the past. Nevertheless, these promising features are confounded by a speleothem's generally low concentration of magnetic minerals, and thus their low magnetic signal, which limits their use in magnetic studies. To bypass this problem, large samples have been commonly used in paleomagnetic studies, but this reduces the time-resolution of the sample. Generally, a sample of around $2 \mathrm{~cm}$ may average ca $100-4000 \mathrm{yr}$ (Strauss et al., 2013) and thus the obtained SV timeresolution is very low.

This paper reports the results of a paleomagnetic study performed on a flowstone sampled at Rio Martino Cave (North Western Alps, Italy). The favourable geologic context of the cave, which is mainly surrounded by meta-ophiolites, makes this flowstone very rich in detrital ferromagnetic components, and thus an ideal geomagnetic field recorder due to its high magnetic remanence properties. Although a high content of detrital material can compromise U/Th dating (Hellstrom, 2006), we have been able to produce a continuous, radiometrically-dated, directional SV record for the area during the last $\sim 10 \mathrm{kyr}$, at a sampling resolution averaging $45 \mathrm{yr}$. Comparison of the new data with archeomagnetic data from Italian artifacts and volcanic rocks and using predictions of global geomagnetic field models, shows that the Rio Martino flowstone represents an excellent recorder of the Earth's magnetic field in the past and demonstrates the potential of speleothems for PSV studies and for the investigation of short-term variations of the geomagnetic field. 
Rio Martino Cave $\left(44^{\circ} 42^{\prime} \mathrm{N}, 7^{\circ} 09^{\prime} \mathrm{E}\right)$ is located in the inner sector of the Western Alps (Northern Italy), which consists of a range of continental and oceanic tectono-metamorphic units bounded by major orogen-scale faulting (Balestro et al., 2014), and exhumed and stacked in the axial sector (Fig. 1). The cave is developed within the Mesozoic carbonate cover of the Palaeozoic Dora Maira (Balestro et al., 2013). This unit is overlain by the Monviso meta-ophiolite complex, a major eclogized remnant of the Ligurian-Piedmont oceanic lithosphere, which in turn is tectonically overlain by the Queyras Schistes Lustrés, interpreted as a fossil accretionary wedge.

The surface above the cave is overlain mainly by glacial deposits. The cave is located at $1530 \mathrm{~m}$ a.s.I. on the right flank of the upper Po valley. It is a spring cave, ca. $3000 \mathrm{~m}$ long, with $200 \mathrm{~m}$ of elevation difference, and is crossed by a small river with an average discharge of $50 \mathrm{l} / \mathrm{s}$ (maximum 200 l/s) (Badino and Chiri, 2005).

The presence of highly magnetized rocks in the cave's catchment (Fig. 1) and the strong magnetic anomalies observed in the Monviso Massif area (Lanza and Meloni, 2006) could induce a magnetic deflection effect in the area. To evaluate the possible effect exerted by the meta-ophiolitic masses and to confirm that it does not exert a significant influence on the paleomagnetic sampling, we used a triaxial fluxgate magnetometer to measure the geomagnetic field components outside and next to the entrance, as well as inside the cave. The computed magnetic inclination values of $60.7^{\circ}$ outside the cave and $60.5^{\circ}$ on the flowstone surface are fully comparable to the 2013 IGRF model of $60.6^{\circ}$ (http://www.ngdc.noaa.gov/geomag-web). Besides, outside the cave we performed some orientation checks by using both the magnetic and the solar compass. The difference between the two declinations was small, ranging from $-5^{\circ}$ to $+2^{\circ}$. Such differences are insignificant and indicate that any local magnetic effects on the paleomagnetic sampling can be considered negligible.

Two sampling campaigns were carried out to collect two cores from the same flowstone, which has accumulated on the side of a seasonally active stream with a high-detrital content. The cores 
were taken $\sim 20-30 \mathrm{~cm}$ apart and drilled using an adapted electric-powered drill. The first core (RMD1), sampled during a campaign in 2010, was not azimuthally oriented. The second core (RMD8), sampled in 2013, was oriented in situ by magnetic compass and inclinometer (figure S1 in the supplemental material). Each core was ca. $60 \mathrm{~cm}$ long and was drilled perpendicular to the flowstone growth axis.

A quarter of each core was dedicated to paleomagnetic analysis. The investigated sub-samples consisted of small slices, about $3 \mathrm{~mm}$ thick (varying from 2.5 to $4 \mathrm{~mm}$ ), cut almost perpendicular to the speleothem's growth direction. Slicing was performed using a very thin non-magnetic saw, which ensured that only $1 \mathrm{~mm}$ of material was consumed during the cut. Following this systematic sampling, we obtained 146 slices from RMD1 and 143 from RMD8. Each slice was positioned in the centre of a non-magnetic plastic cylinder $(2.5 \mathrm{~cm}$ diameter, $2.3 \mathrm{~cm}$ height $)$ that allowed its handling as per standard paleomagnetic samples (Fig. 2).

\section{Methods}

\subsection{U/Th dating and age modelling}

Nineteen solid prisms of $\sim 40 \mathrm{mg}$ ( $\sim 2 \mathrm{~mm}$ wide along the lamina and $1 \mathrm{~mm}$ thick on growth axis) from RMD1 were used for age determination (Table S1 in Supplementary Material). The U/Th dating was performed at the University of Melbourne (Victoria, Australia) following the method of Hellstrom (2003). Briefly, samples were dissolved and a mixed ${ }^{236} \mathrm{U}-{ }^{233} \mathrm{U}-{ }^{229} \mathrm{Th}$ spike was added prior to removal of the carbonate matrix with ion-exchange resin. The purified $U$ and Th fraction was introduced in a dilute nitric acid to a multi-collector inductively coupled plasma mass spectrometer (MC-ICPMS, Nu-Instruments Plasma). The ${ }^{230} \mathrm{Th} /{ }^{238} \mathrm{U}$ and ${ }^{234} \mathrm{U} /{ }^{238} \mathrm{U}$ activity ratios were calculated from the measured atomic ratios using an internally standardised parallel ion- 
counter procedure and calibrated against the HU-1 secular equilibrium standard. Correction for detrital Th content was applied using initial activity ratios of detrital thorium $\left({ }^{230} \mathrm{Th} /{ }^{232} \mathrm{Th}\right)_{\mathrm{i}}$ of $1.3 \pm$ 0.45. This value, and its relative $2 \sigma$ uncertainty, was calculated using a Monte Carlo 'stratigraphic constraint' procedure based on the series of U/Th ages (Hellstrom, 2006). A depth-age model was constructed using a Bayesian Monte Carlo approach following the method described by Drysdale et al. (2005) and Scholz et al. (2012).

\subsection{SEM-EDS analysis}

The mineralogy of the detrital inclusions in the studied flowstone was investigated by dissolving different portions of various thin slabs of the RMD1 core in diluted hydrochloric acid and passing the digests through 0.45 micrometre cellulose acetate filters. The residues, bearing almost all of the non-carbonate mineral inclusion types contained in the speleothem, were observed and analysed with a Cambridge Stereoscan 360 Scanning Electron Microscope housed at the Earth Science Department of the University of Torino, Italy. Analyses were performed using an Oxford Inca X-Act 200 EDS microanalysis equipped with a Link Pentafet detector (thin window), allowing qualitative/quantitative determination of light elements (down to boron). All data were obtained at $15 \mathrm{kV} \mathrm{HT}, 25 \mathrm{~mm}$ WD, probe current range $800 \mathrm{pA}-1.2 \mathrm{nA}$ and analysis time from 60 to $500 \mathrm{~s}$. Primary standardization was performed on SPI Supplies and Polaron Equipment standards, and the system was regularly calibrated against a high-purity metallic Co standard before each experimental session. Data were processed with the Inca 200 Microanalysis Suite Software, version 4.08, and calibrated on natural mineral standards using the ZAF correction method. Analytical data are considered to be only semi quantitative due to the nature of the samples (rough surface of the particles, lack of horizontality, lack of surface polishing). A total of about 1500 analyses was performed on seven samples coming from different portions of the core, 
corresponding to about 200 measurements for each filter, randomly scattered on the filter surface for better representativeness.

Despite the results of magnetic analysis, very few magnetite particles were found in the filtered material, most likely because the single-domain magnetic particles were not retained by the 0.45 $\mu \mathrm{m}$ filter. Magnetite was indeed observed in sandy materials from Rio Martino, being found in the bed sediments of the relatively high-energy environment of the cave stream, rather than as detritus in carbonate flowstone speleothems.

\subsection{Rock magnetic measurements}

All magnetic measurements were performed at the ALP Paleomagnetic Laboratory (Peveragno, Italy). Rock magnetic experiments were performed on representative samples from both cores. Rock magnetism was investigated by low-field susceptibility $\left(k_{m}\right)$ and natural remanent magnetization $\left(\mathrm{J}_{\mathrm{r}}\right)$ measurements using a KLY3 kappabridge and a JR6 spinner magnetometer with a sensitivity of the order of $10^{-8} \mathrm{SI}$ and $10^{-6} \mathrm{~A} / \mathrm{m}$, respectively. Susceptibility was measured at least five times per sample in order to calculate a mean value. Standard deviation is low and normally less than $5 \%$ for specimens associated with a susceptibility spike; uncertainty grows to $20-35 \%$ for the remaining specimens, characterized by negative (diamagnetic) susceptibility values. All samples were weighed to get the mass-normalized susceptibility $\left(\chi, \mathrm{m}^{3} \mathrm{~kg}^{-1}\right)$ and intensity $(J$, $\mathrm{Am}^{2} / \mathrm{Kg}$ ). Their values are represented as a function of the core depth in figure $\mathrm{S} 2$ of the supplemental material.

Isothermal Remanent Magnetization (IRM) curves were obtained with an ASC pulse magnetizer, applying stepwise increasing fields up to $1 \mathrm{~T}$. Thermal demagnetization of a three-axis composite IRM was also performed on representative samples (Lowrie, 1990). An IRM was imparted with an 
190

191

192

193

194

195

ASC pulse magnetizer along the sample's three orthogonal axes, applying first a maximum $1.5 \mathrm{~T}$, then a medium 0.3 T and finally a minimum 0.1 T magnetic field. Crossover plots of IRM curves and alternating field (AF) demagnetization of the saturation IRM (SIRM) were carried out to investigate the magnetic grain size (Symons and Cioppa, 2000).

Finally, hysteresis cycles were obtained by a Vibrating Sample Magnetometer (VSM, LakeShore 7410 - Maximum applied field $B_{\max }= \pm 1 \mathrm{~T} ; \mathrm{H}= \pm 10.000$ Oe $/ 976.000 \mathrm{~A} / \mathrm{m}$ ) at the Istituto Nazionale di Ricerca Metrologica (INRIM, Torino) and interpreted by RockMag Analyzer 1.0 software (Leonhardt, 2006). All specimens were AF demagnetized stepwise up to $100 \mathrm{mT}$ with a ASC-D 2000 equipment. Representative twin specimens were also stepwise thermally demagnetized with a Schonstedt TSD-1 furnace.

\section{Results}

\subsection{Chronology}

All the U/Th ages obtained from RMD1 were in stratigraphic order within the associated uncertainties, except for two samples that were consequently rejected as outliers (Table S1 in Supplementary Material). Macroscopic and thin-section analyses of core RMD1 shows no growth interruption along its length. Age modelling performed on RMD1 indicates that the flowstone grew continuously between $0.56 \pm 0.06 \mathrm{ka}$ and $9.7 \pm 1.6 \mathrm{ka}$ b2k (Fig. 3). The mean growth rate is $0.058 \mathrm{~mm} / \mathrm{yr}$, which implies a mean time-resolution of ca. $60 \mathrm{yr}$ ( $3 \mathrm{~mm}$ specimen $+1 \mathrm{~mm}$ cut) for the PSV record. The time averaged in each $3 \mathrm{~mm}$ slice sample is ca. $45 \mathrm{yr}$. The age of RMD8 was inferred by comparing clearly visible growth layers (Fig. 2a) between the two cores, associated with spikes in both the magnetic mass susceptibility and mass magnetization (figure S2 of the supplemental material). 
The mineralogy of the detrital portion in the RMD1 core is in strong accord with the composition 215 of the surrounding lithology. Apart of the calcareous formation in which the cave has developed, the main rocks in the area are prasinites, amphibolites and serpentines. Minerals were grouped by similar chemistry, with some simplifications: as stated above, analyses were only semiquantitative. The main identified groups are: iron oxides (without magnetite, discriminated by morphological features), magnesium silicates (other than serpentine), serpentine group, white mica group, feldspar, tremolite-actinolite amphiboles, other amphiboles (mainly hornblende), epidote group, chlorite group, quartz and accessories. The main minerals (Fig. 4) are represented by iron oxides (not distinguishable by chemistry for the reason explained above), magnesium silicates and serpentine group minerals. Iron oxides are mostly irregular in shape as if they had undergone reworking from the stream or by feedwater (Perkins, 1996). In few cases, a framboidal shape suggests in situ growth.

\subsection{Magnetic mineralogy}

The mass magnetic susceptibility of the specimens strongly varies. It mostly shows a prevailing diamagnetic phase with small negative values (from -7 to $0 \times 10^{-9} \mathrm{~m}^{3} \mathrm{~kg}^{-1}$ with a mean value of $-4 \mathrm{x}$ $\left.10^{-9} \mathrm{~m}^{3} \mathrm{~kg}^{-1}\right)$, alternating with high positive spikes, up to $970 \times 10^{-9} \mathrm{~m}^{3} \mathrm{~kg}^{-1}$, suggesting a very low concentration of magnetic minerals in these specimens. Calcite bulk susceptibility is $-12.09 \mu \mathrm{SI}$; its mass susceptibility is about $-4.46 \times 10^{-9} \mathrm{~m}^{3} \mathrm{~kg}^{-1}$ (Almqvist et al., 2010). Since the literature value for the susceptibility of calcite refers to single crystal, we can assume that the mass susceptibility for calcite in the speleothem is slightly higher, because of mineral porosity. Assuming a constant diamagnetic contribution mostly due to calcite, the relative variability of magnetic susceptibility is 
indicative of variations of the concentration of magnetic minerals: a mean $\chi$ value of $-4 \times 10^{-9} \mathrm{~m}^{3}$

$\mathrm{kg}^{-1}$ can be assumed to be representative of the "standard" content in magnetite, while high values represent for pulses of higher detrital input.

The natural magnetization intensity $\left(J_{r}\right)$ strongly varies from specimen to specimen, being on average around $1-10 \times 10^{-6} \mathrm{Am}^{2} \mathrm{~kg}^{-1}$ with spikes up to $80 \times 10^{-6} \mathrm{Am}^{2} \mathrm{~kg}^{-1}$. The variations of these two bulk parameters are correlated; the computed correlation coefficients are $r=0.87$ and $r=$ 0.76 for RMD1 and RMD8, respectively. This corroborates the hypothesis that their values are essentially controlled by changes in concentration of the magnetic oxide.

IRM acquisition curves from representative samples saturate at relatively low field (around 0.3 T), indicating the presence of low coercivity minerals (Fig. 5a). The IRM acquisition data were further analyzed applying the MAX UnMix software (Maxbauer et al., 2016) to six flowstone slices and to sand collected from the bed of the cave spring. For three specimens, i.e. RM101 and RM134 flowstones and the sand, only one magnetic component was identified with Bh and DP values fully consistent with detrital magnetite $(\mathrm{Bh}=1.46, \mathrm{DP}=0.40)$. In the remaining cases, two components were detected, one as above, and the other pointing to higher-coercivity magnetite. The computed S-ratio $\left(\mathrm{S}_{-0.3 \mathrm{mT}}\right)$ ranges from 0.95 to 1.00 .

During the thermal demagnetization of the orthogonal IRM components (Lowrie, 1990), two typical behaviors were observed, which are independent of the magnetization intensity of the specimens. The first (e.g. sample RM68a), representing about the $80 \%$ of the measured specimens, suggests that the primary remanence is dominated by a soft magnetic carrier, demagnetized at ca $350-450{ }^{\circ} \mathrm{C}$, which is interpreted as a titanomagnetite (Fig. 5b). The second (e.g. sample RM44a), in the remaining $20 \%$, is characterized by a first drop in the magnetization intensity between 200 and $300{ }^{\circ} \mathrm{C}$, which may be speculatively related to the existence of maghemite (Pan et al., 2000), even though this evidence is not sufficient to unambiguously 
260 
Speleothems can potentially offer very useful records of PSV and the remanence acquisition mechanisms in speleothems have been previously studied in detail (e.g., Lascu and Feinberg, 2011; Strauss et al., 2013, and reference therein). In order to provide a reliable PSV record, the magnetization should be acquired and locked soon after the calcium carbonate film is deposited on a speleothem (almost instantaneously). Following Strauss et al. (2013), lock-time for a speleothem is sub-annual and the magnetization is a DRM. Synchronicity between crystallization and magnetization has been tested experimentally by synthetic stalagmite growth (Morinaga et al., 1989), confirming the short time-lapse in acquiring magnetization parallel to the ambient field direction.

To test if this requirement is encountered in Rio Martino flowstone and thus to check for its reliability as a PSV recorder, we measured both the Anisotropy of Magnetic Susceptibility (AMS) and the Anisotropy of Isothermal Remanent Magnetization (AIRM) on two selected sets of samples from RMD1 (azimuthally non-oriented core), each comprising a time interval of ca 1000 yr. The first set comprised 16 samples (SP200 to SP260) from $4.26 \pm 0.23$ to $3.30 \pm 0.03 \mathrm{ka}$, and the second set 14 samples (SP346 to SP397) from $7.76 \pm 0.12$ to $6.91 \pm 0.11$ ka. A difference of $20^{\circ}$ in the mean magnetic ChRM inclination distinguished these two sets of specimens. The AMS was measured by a KLY-3 kappabridge. The results obtained on both sets of samples show a welldefined (confidence angles $<15^{\circ}$ ) mean minimum susceptibility axis, $k_{3}$, which is statistically vertical and perpendicular to the flowstone growth laminae (Fig. 6a). For the AIRM measurements, each specimen was first AF demagnetized using a tumbling $2 \mathrm{G}$ demagnetizer at $60 \mathrm{mT}$ peak field and then given an isothermal remanent magnetization (IRM) with a steady field of $20 \mathrm{mT}$ using an AGICO PUM-1 pulse magnet. After measurement with the spinner magnetometer, the sequence was repeated for a total of 12 different orientations of the IRM in order to calculate the anisotropy tensor. The experiment (Fig. 6b-c) shows that for both sets, the maximum IRM anisotropy axis $I_{1}$ is 
concordant or statistically indistinguishable from the mean ChRM direction, showing no relation with the speleothem growth laminae. This shows that ChRM direction is due to the statistical alignment of the magnetic particle and fully agrees with the conclusions of Zhu et al. (2012), who performed both AMS and AIRM on stalagmites. They found that the AMS was dominated by the calcite fabric, being the minimum susceptibility axis $k_{3}$ aligned perpendicular to the stalagmite growth laminae, while the AIRM fabric showed the maximum remanence axis $I_{1}$ almost parallel to the NRM direction. These data all point to a detrital origin of the magnetization, with the geomagnetic field control in the orientation of the ferromagnetic minerals.

\subsection{Characteristic Remanent Magnetization determination}

Demagnetization results are represented by intensity-decay curves and plotted in Zijderveld diagrams (Fig. 7). Most of the specimens are characterized by a small viscous remanent magnetization (VRM), which is easily removed at an AF field of 15-20 mT. The remaining demagnetization path is linear and points to the origin, indicating a stable remanent magnetization; this component has been interpreted as the Characteristic Remanent Magnetization (ChRM). The ChRM direction is mostly well defined and characterized by low MAD values (lower than $8^{\circ}$ for the $91 \%$ of the studied samples). AF and thermal demagnetization results obtained from twin specimens are very similar (Fig. 7), confirming the reliability of the ChRM direction (Fig. 8; Table S2 in Supplementary Material). In the thermal demagnetization (Fig. 7b and 7d), an inflection in the intensity decay curve it is observable at ca. $150{ }^{\circ} \mathrm{C}$. As suggested by Strauss et al. (2013) the decay could be correlated with the occurrence of goethite, not detected however by any other experiment. The AF demagnetization treatment has been preferred rather than the thermal demagnetization, as it permits the further use of the same samples for paleoenvironmental and relative paleointensity investigations through Anhysteretic Remanent 
Magnetization (ARM) measurements. Therefore, all samples were systematically AF demagnetized and ChRM directions were obtained from the AF demagnetization results. Demagnetization behavior in samples with low- and high-remanence (spike) does not change significantly except for specimens where serpentinite clasts were recognized.

\section{Directional Paleosecular Variation during Holocene}

Paleomagnetic directions obtained from the two cores (reported in Table S2 of Supplementary material) are plotted versus depth from the top of the core in Figure 9. Some spikes in declination show a strong correspondence with atypical MDF values, lower/higher than 20/60 mT. These deflected directions have been ascribed to the presence of small serpentinite lithic fragments and were thus rejected. The declination of RMD1, which was not azimuthally oriented, has been recovered after adjustment of its mean value to the Geocentrical Axial Dipole (GAD) calculated at Rio Martino according to the following procedure: first, the mean direction of RMD1 has been calculated for the last $10 \mathrm{kyr}$ and then its deviation from the GAD value has been computed. The difference in declination between the core and the GAD has been extracted from each declination value of the RMD1 core.

Generally, directions obtained from both RMD1 and RMD8 are in good agreement with each other and data reproducibility is high (Fig. 9). This is particularly evident for the inclination data at depths between 200.0 and $600.0 \mathrm{~mm}$, where the two records match each other. Instead, in some cases, mostly at depths from 150.0 to $200.0 \mathrm{~mm}$, differences in inclination of around $20^{\circ}-25^{\circ}$ are observed. The cause of such differences is not clear, even though uncertainties during sampling (slices not perfectly perpendicular to the flowstone growth) and deflections related to a possible anisotropy effect connected to the calcite crystals growth cannot be completely excluded. To 
guarantee the high quality of the new data, only ChRM directions characterized by MAD values lower than $6^{\circ}$ have been used in the plots. Directional data of each core have been kept clearly distinguishable, because only RMD1 was directly dated and even though the paleomagnetic records from the two cores are consistent and despite the fact that the two cores are only $30 \mathrm{~cm}$ apart, their simultaneous growth cannot be fully guaranteed.

The paleosecular variations registered by the Rio Martino speleothem are compared with spot archeomagnetic directions obtained from dated archeological structures and volcanic rocks from Italy. The data from the in situ archeological material are taken from the Italian archeomagnetic dataset (Tema et al., 2006; Tema, 2011) updated by some recently published results (Malfatti et al., 2011; Kapper et al., 2014; Tema et al., 2013; 2015; 2016). The data from the Italian volcanic eruptions have been downloaded from the GEOMAGIA50.v3 database (Brown et al., 2015). All data have been relocated at the geographic coordinates of Rio Martino via the virtual geomagnetic pole method (Noel and Batt, 1990). The comparison shows that the archeomagnetic and volcanic data generally fit very well to the speleothem directions (Fig. 10). Some discrepancies in declination can be observed around 1000 AD. For this period the speleothem declination values are very low and quite dispersed. Nevertheless, it is particularly interesting to note that for the BC period, the available archeomagnetic data, even if very limited and often accompanied by large error bars, are in excellent agreement with the new data, in spite of the speleothem inclination being systematically higher. Recently, Ponte et al. (2016) noticed that the inclination values in speleothems seem to vary as a function of the orientation of the calcite growth. To check for this effect, we calculated the mean paleomagnetic direction for both RMD1 and RMD8 applying Fisher Statistics, selecting ChRMs with MAD $<6^{\circ}$. Their mean directions (RMD1: $D=358.8^{\circ}, I=65.1^{\circ}, \alpha_{95}$ $=1.9^{\circ} ; \mathrm{RMD} 8: \mathrm{D}=2.4^{\circ}, \mathrm{I}=65.8^{\circ}, \alpha_{95}=1.7^{\circ}$ ) are close to the GAD at Rio Martino's geographic coordinate $\left(D=0^{\circ}, I=63^{\circ}\right)$, even if statistically distinguishable. However, AIRM shows a reliable 
consistency between the mean ChRM and the mean $\mathrm{I}_{1}$ axis, which confirms that the orientation of the ferromagnetic minerals was mainly controlled by the geomagnetic field present during speleothem accumulation. This substantiates the high potential of Rio Martino speleothems to continuously and reliably register the Earth's magnetic field, offering a unique source of high quality data for the BC period where in situ archeological artifacts are very scarce.

The new data are also compared with the predictions of global geomagnetic field models. Here, we have used for comparison the pfm9k.1a (Nilsson et al., 2014) and the SHA.DIF.14k (PavónCarrasco et al., 2014) models that are the most recently published global geomagnetic models for the Holocene. There is good agreement between the speleothem records and the global models predictions, confirming some interesting features of the Earth's magnetic field in the past. The eastward declinations around 1000 BC mainly observed in the SHA.DIF.14k model are observed in the speleothem data for the same time period, and also show high declination values. For the 4000-2000 BC period, only small declination variations are shown by the speleothem data, in agreement with the pfm9k model's predictions, while the declination peaks seen in the SHA.DIF.14k model (e.g. around 3600 BC) are not confirmed by the speleothem data. For periods older than $5000 \mathrm{BC}$, speleothem records show generally higher declination values compared to the model predictions and other archeomagnetic data. Interestingly, similar eastward declination values were found for cave sediments in Switzerland (Kapper et al., 2014). Regarding the inclination data, good agreement can be observed for the periods $6000-3500$ BC and 500 BC-500 AD. However, around $1000 \mathrm{BC}$, speleothems show an interesting high-inclination peak that is not observed in the models or sustained by the available archeomagnetic data. This peak is actually only observed on the data from the RMD8 core and definitely more independent records are necessary to investigate if it corresponds to a real abrupt directional change (as it corresponds also to high declination values) of the geomagnetic field at this time period. For the $7500 \mathrm{BC}$ to $6000 \mathrm{BC}$ 
period, the speleothem records show continuously increasing inclination with a peak around 6000 $\mathrm{BC}$ that seems to be in agreement with the model's predictions.

\section{Conclusions}

Some outstanding characteristics of the Rio Martino flowstone, such as its continuous growth, the well-constrained chronology and the intense magnetic signal, make its paleomagnetic directional record for the Holocene in the northwestern Italy particularly appropriate for PSV investigation. The high magnetic signal permits a high-resolution record of around $60 \mathrm{yr}$ per data point; the regular scatter of paleomagnetic data through time shows an almost constant distribution of directional data though the Holocene.

The obtained directional results are well defined and offer a unique, almost continuous, secular variation record for the last $\sim 10,000$ years. Although some discrepancies can be observed, comparison with archeomagnetic data and global geomagnetic field models confirms the high potential of these speleothems to the reconstruction of the Earth's magnetic field variations in the past.

Our results show that the Rio Martino flowstones are not affected by recrystallization effects or secondary alterations. The speleothems do not show any inclination shallowing when compared with model predictions, and in some cases show high inclination peaks that are not observed by the models (e.g. around $3800 \mathrm{BC}, 1000 \mathrm{BC}, 800 \mathrm{AD}$ ).

The record characteristics overcome some typical features affecting both clastic sedimentary and the archeomagnetic PSV records, including the smoothness of the magnetic data in the case of the former and the presence of temporal gaps and uneven data distribution in the case of the latter.

The high resolution obtained points to the possibility of detecting short and abrupt geomagnetic field changes by studying a wide variety of Earth Magnetic Field variations at a timescale from tens 
of years to the millennia and highlights the importance of regional differences when modelling the Earth's field. The use of speleothem records for PSV reconstructions can be particularly important for the prehistoric period where other sources if data coming from archeological artifacts or welldated volcanic eruptions are scarce.

\section{Acknowledgments}

We thank the Associazione Gruppi Speleologici Piemontesi (AGSP) for the logistical support during field campaign and in particular Raffaella Zerbetto for her kindness and competence. E. Ferrara (INRIM) is gratefully acknowledged for hysteresis measurements and A. Roncioni for his support in coring operations. J.M. Feinberg and two anonymous referees are thanked for helpful reviews that greatly improved the manuscript. This paper is dedicated to the memory of Prof. Roberto Lanza who enthusiastically supported this study during the last months of his life giving fundamental advices and suggestions.

\section{References}

Almqvist, B.S.G., Herwegh, M., Schmidt, V., Pettke, T., Hirt, A.M., 2010. Magnetic susceptibility as a tool to study deformed calcite with variable impurity content. Geochemistry Geophysics Geosystems, 11, Q01Z09, doi:10.1029/2009GC002900

Badino, G., Chiri, M., 2005. First data from the underground meteorological station of Rio Martino, Italy. Hellenic Speleological Society. 21-28 August 2005, Kalamos, Greece.

Balestro, G., Fioraso, G., Lombardo, B., 2013. Geological map of the Monviso massif (Western Alps). Journal of Maps, 9, 4, 623-634, doi: 10.1080/17445647.2013.842507

Balestro, G., Festa, A., Tartarotti, P., 2014. Tectonic significance of different block-in-matrix structures in exhumed convergent plate margins: examples from oceanic and continental HP 
rocks in Inner Western Alps (northwest Italy). International Geology Review. DOI: 10.1080/00206814.2014.943307.

Brown, M.C., Donadini, F., Korte, M., Nilsson, A., Korhonen, K., Lodge, A., Lengyel, S.N., Constable, C.G., 2015. GEOMAGIA50.v3: 1.General structure and modifications to the archeological and volcanic database. Earth Planets Space, 67:83, doi:10.1186/s40623-015-0232-0

Drysdale, R.N., Zanchetta, G., Hellstrom, J.C., Fallick, A.E., Zhao, J.X., 2005. Stalagmite evidence for the onset of the Last Interglacial in southern Europe at 129+/-1 ka. Geophysical Research Letters 32, 1-4.

Dunlop, D.J., 2002. Theory and application of the Day plot $\left(M_{r s} / M_{s}\right.$ versus $\left.H_{c r} / H_{c}\right) 1$. Theoretical curves and tests using titanomagnetite data. J. Geophys. Res., 107, 2056, doi: 10.1029/2001JB000486

Fairchild, I.J., Smith, C.L., Baker, A., Fuller, L., Spötl, C., Mattey, D., McDermott, F., 2006. Modification and preservation of environmental signals in speleothems. Earth Science Reviews, 75, 105-153, doi:10.1016/j.earscirev.2005.08.003

Font, E., Veiga-Pires, C., Pozo, M., Carvallo, C., de Siqueira Neto, A.C., Camps, P., Fabre, S., Mirão, J., 2014. Magnetic fingerprint of southern Portuguese speleothems and implications for paleomagnetism and environmental magnetism. Journal of Geophysical Research, 119, 7993-8020, doi:10.1002/2014JB011381.

Hellstrom, J.C., 2003. Rapid and accurate U/Th dating using parallel ion-counting multicollector ICP-MS. Journal of Analytical Atomic Spectrometry 18, 1346-1351

Hellstrom, J.C., 2006. U-Th dating of speleothems with high initial 230Th using stratigraphical constraint. Quaternary Geochronology, 1, 289-295. 
Jaqueto, P., Trindade, R.I.F., Hartmann, G.A., Novello, V.F., Cruz, F.W., Karmann, I., Strauss B.E., Feinberg, J.M., 2016. Linking speleothem and soil magnetism in the Pau d'Alho cave (central South America). Journal of Geophysical Reseach, 121, doi:10.1002/2016JB013541.

Johnson, H.P., Lowrie, W., Kent, D.V., 1975. Stability of Anhysteretic Remanent Magnetization in fine and coarse magnetite and maghemite particles. Geophysical Journal of the Royal astronomical Society, 41, 1-10.

Kapper, L., Anesin, D., Donadini, F., Angelucci, D., Cavulli, F., Pedrotti, A., Hirt, A., 2014. Linking site formation processes to magnetic properties. Rock and archaeomagnetic analysis of the combustion levels at Riparo Gaban (Italy). Journal of Archaeological Science, 41, 836-855.

Kapper, L., Donadini, F., Mauvilly, M., Panovska, S., Hirt, A.M., 2014. New directional archaeomagnetic data of burned cave sediments from Switzerland and geomagnetic field variations in Central Europe. Geophysical Journal International, 198, 1208-1221, doi:10.1093/gji/ggu184

Lanza, R., Meloni, A., 2006. The Earth's Magnetism. An Introduction for Geologists. Springer,278 pp.

Lascu, I., Feinberg, J.M., 2011. Speleothem magnetism. Quaternary Science Reviews, 30, 33063320.

Lascu, I., Feinberg, J.M., Dorale, J.A., Cheng, H., Edwards, R.L., 2016. Age of the Laschamps excursion determined by U-Th dating of a speleothem geomagnetic record from North America. Geology, 44,139-142, doi: 10.1130/G37490.

Latham, A.G., Schwarcz, H.P, Ford, D.C., 1986. The paleomagnetism and U-Th dating of Mexican Stalagmite, Das2. Earth Planetary Science Letters, 79, 195-207. 
Latham, A. G., Ford, D.C., Schwarcz, H.P., Birchall, T., 1989. Secular variation from Mexican stalagmites: Their potential and problems. Physics of the Earth and Planetary Interiors, 56, 34-48.

Lean, C.B., Latham, A.C., Shaw, J., 1995. Palaeosecular variation from a Vancouver Island Stalagmite and comparison with Contemporary North American records. J. Geomag. Geoelectr., 47, 71-87.

Leonhardt, R., 2006. Analyzing rock magnetic measurements: The RockMagAnalyzer 1.0 software. Computers \& Geosciences, 32, 1420-1431.

Lowrie, W., 1990. Identification of ferromagnetic minerals in a rock by coercivity and unblocking temperature properties. Geophysical Research Letters, 17, 159-162.

Malfatti, J., Principe, C., Gattiglia, G., 2011. Archeaomagnetic investigation of a metallurgical furnace in Pisa (Italy). Journal of Cultural Heritage, 12, 1-10.

Mandea, M., Olsen, N., 2009. Geomagnetic and Archeomagnetic Jerks: Where Do We Stand? Eos, Transactions, American Geophysical Union, 90, 24, 208-208.

Maxbauer, D.P., Feinberg, J.M., Fox, D.L., 2016. MAX UnMix: A web application for unmixing magnetic coercivity distributions. Computers \& Geosciences, 95, 140-145.

Morinaga, H., Inokuchi, H., Yaskawa, K., 1989. Palaeomagnetism of stalagmites (speleothems) in SW Japan. Geophys. J., 96, 519-528.

Nilsson, A., Holme, R., Korte, M., Suttie, N., Hill, M., 2014. Reconstructing Holocene geomagnetic field variation: new methods, models and implications. Geophysical Journal International, $198,1,229-248$.

Noel, M., Batt, C.M., 1990. A method for correcting geographically separated remanence directions for the purpose of archaeomagnetic dating. Geophysical Journal International, $102,753-756$. 
Openshaw, S., Latham, A., Shaw, J., 1997. Speleothem Palaeosecular Variation Records from China: Their contribution to the coverage of Holocene Palaeosecular Variation Data in East Asia. J. Geomag. Geoelectr., 49,485-505.

Osete, M. L., Martin-Chivelet, J., Rossi, C., Edwards, R.L., Egli, R., Munoz-Garcia, M.B., Wang, X.F., Pavon-Carrasco, F.J., Heller, F., 2012. The Blake geomagnetic excursion recorded in a radiometrically dated speleothem. Earth Planetary Science Letters, 353, 173-181.

Pan, Y., Zhu, R., Banerjee, S.K., Gill, J., Williams, Q., 2000. Rock magnetic properties related to thermal treatment of siderite: behaviour and interpretation. Journal of Geophysical Research, 105, 783-794.

Pavón-Carrasco, F.J., Osete, M.L., Torta, J.M., De Santis, A., 2014. A geomagnetic field model for the Holocene based on archaeomagnetic and lava flow data. Earth Planetary Science Letters, $388,98-109$.

Perkins, A.M., 1996. Observations under microscopy of magnetic minerals extracted from speleothems. Earth and Planetary Science Letters, 139, 281-289.

Ponte, J., Font, E., Veiga-Pires, C., Hillaire, M.C., 2016. Paleomagnetism in speleothems: Influence of calcite growth dip on the natural remanent magnetization. EGU General Assembly 2016, 17-22 April, Vienna, p.7199

Richards, D.A., Dorale, J.A., 2003. Uranium-series chronology and environmental applications of speleothems. Review in Mineralogy and Geochemistry, 52, 407-460.

Rolph, T.C., Vigliotti, L., Oldfield, F. 2004. Mineral magnetism and geomagnetic secular variation of marine and lacustrine sediments from central Italy: timing and nature of local and regional Holocene environmental change. Quaternary Science Review, 23, 1699-1722.

Scholz, D., Hoffmann, D.L., Hellstrom, J., Bronk Ramsey, C., 2012. A comparison of different methods for speleothem age modelling. Quaternary Geochronology. 14, 94-104. 
Strauss, B.E., Strehlau, J.H., Lascu, I., Dorale, J.A., Penn, R.L., Feinberg, J.M., 2013. The origin of magnetic remanence in stalagmites: observations from electron microscopy and rock magnetism. Geochemistry Geophysics Geosystems, 14, doi: 10.1002/2013GC004950

Symons, D.T.A., Cioppa, M.T., 2000. Crossover Plots: a useful method for plotting SIRM data in paleomagnetism. Geophysical Research Letters, 27 (12), 1779-1782.

Tema, E., 2011. Archaeomagnetic Research in Italy: Recent achievements and future perspectives. In: The Earth's Magnetic Interior, IAGA Special Sopron Book Series, Volume 1, Chapter 15, pp. 213-233. Eds: Petrovsky, E., Herrero-Bervera, E., Harinarayana, T., Ivers, D., Springer, doi: 10.1007/978-94-007-0323-0_15.

Tema, E., Hedley, I., Lanos, Ph., 2006. Archaeomagnetism in Italy: A compilation of data including new results and a preliminary Italian Secular Variation curve. Geophysical Journal International, 167, 1160-1171.

Tema, E., Fantino, F., Ferrara, E., Lo Giudice, A., Morales, J., Goguitchaichvili, A., Camps, P., Barello, F., Gulmini, M., 2013. Combined archaeomagnetic and thermoluminescence study of a brick kiln excavated at Fontanetto Po (Vercelli, Northern Italy). J. Arch. Science, 40 (4), 2025-2035.

Tema, E., Camps, P., Ferrara, E., Poidras, T., 2015. Directional results and absolute archaeointensity determination by the classical Thellier and the multi-specimen DSC protocols for two kilns excavated at Osterietta, Italy. Studia Geophysica Geodaetica, 59, 554577.

Tema, E., Ferrara, E., Camps, P., Conati Barbaro, C., Spatafora, S., Carvallo, C., Poidras, Th., 2016. The Earth's magnetic field in Italy during the Neolithic period: New data from the Early Neolithic site of Portonovo (Marche, Italy). Earth and Planetary Science Letters, 448, 49-61. 
564 Turner, G.M., Thompson, E., 1981. Lake sediment record of the geomagnetic secular variation in 565 Britain during Holocene times. Geophysical Journal of the Royal Astronomical Society, 65 (3), $566 \quad 703-725$.

567 Vigliotti, L., 2006. Secular variation record of the Earth's magnetic field in Italy during the 568 Holocene: constraints for the construction of a master curve. Geophys. J. Int., 165, 414-429. 569 Xie, S., Evershed, R.P., Huang, X., Zhu, Z., Pancost, R.D., Meyers, P.A., Gong, L., Hu, C., Huang, J., 570 Zhang, S., Gu, Y., Zhu Y., 2013. Concordant monsoon-driven postglacial hydrological changes 571 in peat and stalagmite records and their impacts on prehistoric cultures in central China. Geology, 41, 827-830, doi:10.1130/G34318.1

573 Zhu, Z., Zhang, S., Tang, C., Li, H., Xie, S., Ji, J., Xiao, G., 2012. Magnetic fabric of stalagmites and its 574 formation mechanism. Geochemistry Geophysics Geosystems, 13, doi: 10.1029/2011GC003869. 


\section{Figure Caption}

Figure 1. a) Structural sketch map of the Western Alps; b) 3D reconstruction of the Inner Western Alps in the Rio Martino zone (modified after Balestro et al., 2014). The square indicates the location of the Rio Martino Cave. Note: the region highlighted in the small inset map is not the same as the one shown in the enlargement.

Figure 2. a) Part of core RMD8; b) part of the flowstone systematically cut and sampled in $3 \mathrm{~mm}$ thick slices; c) the amagnetic plastic cylindrical holder created in order to fix the small samples in the centre of the cylinder and treat them as standard paleomagnetic samples.

Figure 3. Age-depth model for RMD1 core. The age is expressed both in ka AD and in b2k (before 2 ka).

Figure 4. The distribution of the mineral species in the insoluble (detrital) fraction of Rio Martino speleothem. The picture is the sum of ca 1500 EDS determinations from seven different portions from the same core. The "accessory minerals" are species $<2.5 \%$ of the analyzed particles, for each sample and includes rutile, zircon, monazite, apatite (mainly apatite-F), sphene, xenotyme, galena, pyrite, ilmenite, barite.

Figure 5. a) Isothermal remanent magnetization (IRM) acquisition curves; b) thermal demagnetization of a composite three-axes IRM (Lowrie, 1990); c) crossover plots (Symons and Cioppa, 2000).

Figure 6. Equal area stereographic projections of the eigenvectors for a) the anisotropy of magnetic susceptibility, and for b) and c) isothermal remanent magnetization, where the maximum, intermediate, and minimum eigenvectors are denoted by squares, triangles, and circles, respectively. The $95 \%$ confidence ellipses for the eigenvectors are shown by unfilled 
600

601

602

603

604

605

606

607

608

609

610

611

612

613

614

615

616

617

618

619

620

ellipses. The mean ChRM directions and their alpha95 errors for specimens SP200 to SP260 (b) and SP346 to SP397 (c) are denoted by stars with grey ellipses.

Figure 7. Thermal and AF demagnetization results from twin specimens from samples a-b) RM7 and c-d) RM20 plotted in intensity decay plots (left) and Zijderveld diagrams (right). Symbols: full dots = declination; open dots $=$ apparent inclination

Figure 8. Equal-area projections of the ChRM directions for five samples obtained from a) AF and b) thermal demagnetization on twin specimens. The star represents the mean value calculated for each group of samples following a Fisherian distribution.

Figure 9. a) Declination and b) inclination data from cores RMD1 (red) and RMD8 (blue) plotted versus depth in mm from the top of the core.

Figure 10. a) Declination and b) inclination plots of the RMD1 (red) and RMD8 (blue) compared with the Italian archaeomagnetic data from archeological artefacts (green diamonds) and volcanic rocks (black squares) and the pfm9k (magenta line) and SHA.DIF.14k (black line) global geomagnetic field models. All directions are calculated at the geographic coordinates of Rio Martino $\left(44.7^{\circ} \mathrm{N}, 7.15^{\circ} \mathrm{E}\right)$. Age is given both as Calendar Age (year AD) and b2k (before $2 \mathrm{ka}$ ).

\section{Figure caption of the Supplemental material}

Figure S1. a) Photograph of the flowstone's sampling and b) of the device to orient the core.

Figure S2. a) Mass susceptibility and b) mass remanence intensity from RMD1 (red) and RMD8 (blue) plotted versus depth in $\mathrm{mm}$ from the top of the core.

Figure S3. Hysteresis curves (mass magnetization versus applied field) for specimens SP421 and SP460. In a) uncorrected curves; in b) slope-corrected for diamagnetic effect curves. 
Table S1. Corrected U/Th ages for RMD1 core. Isotope ratios are expressed as activity ratios standardized to the HU-1 secular equilibrium standard. Ages have been calculated using decay constants of $9.195 \times 10^{-6}\left({ }^{230} \mathrm{Th}\right)$ and $2.835 \times 10^{-6}\left({ }^{234} \mathrm{U}\right)$. Depths are from top.

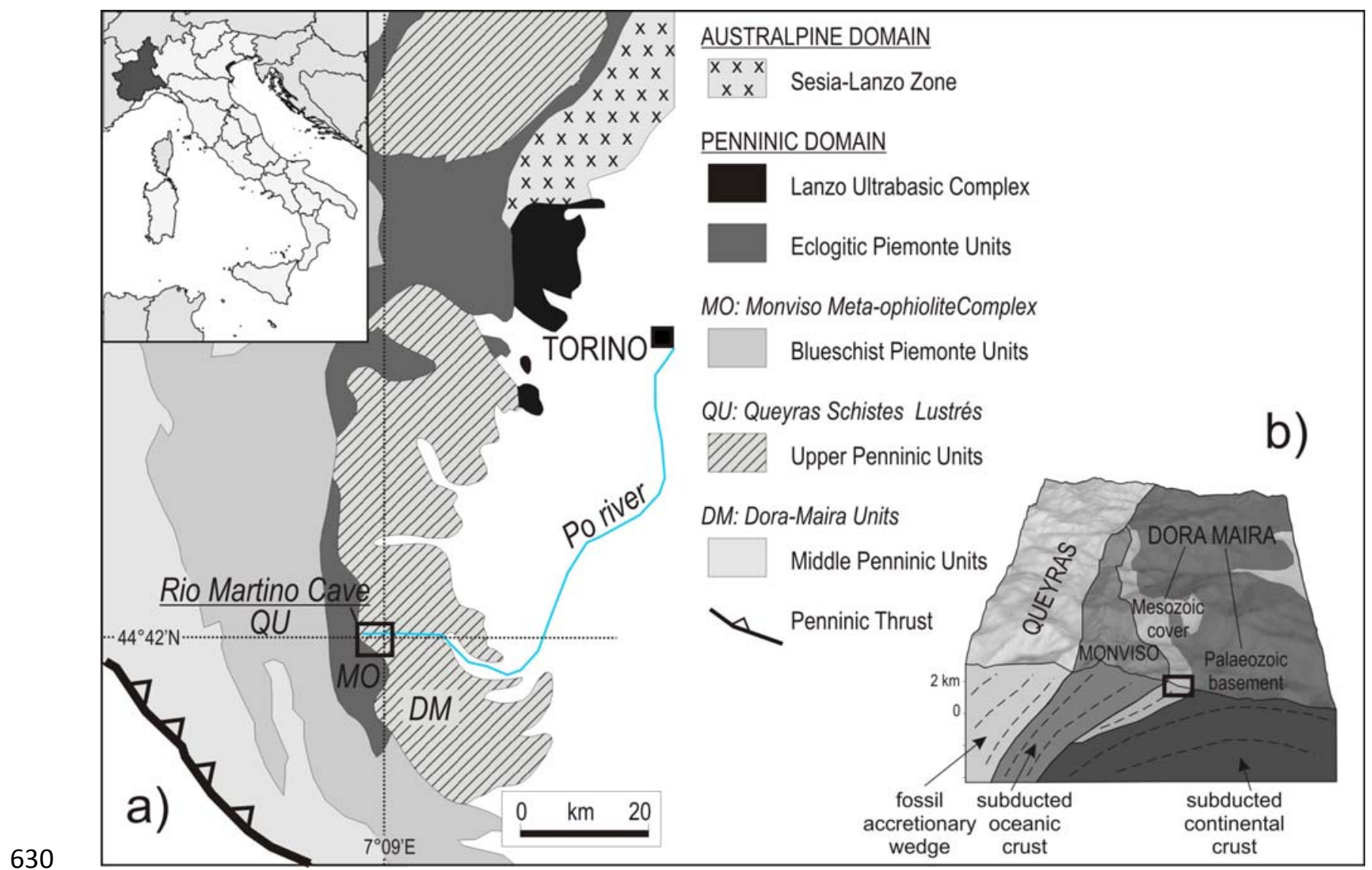



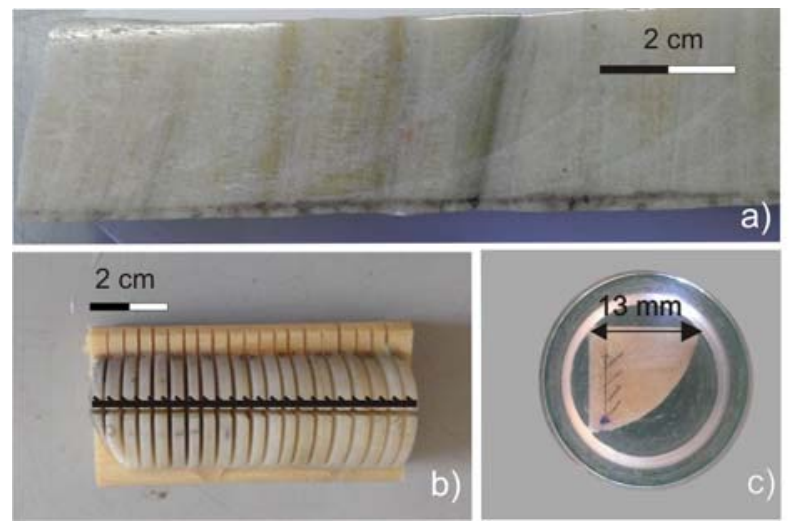

633 Figure 2

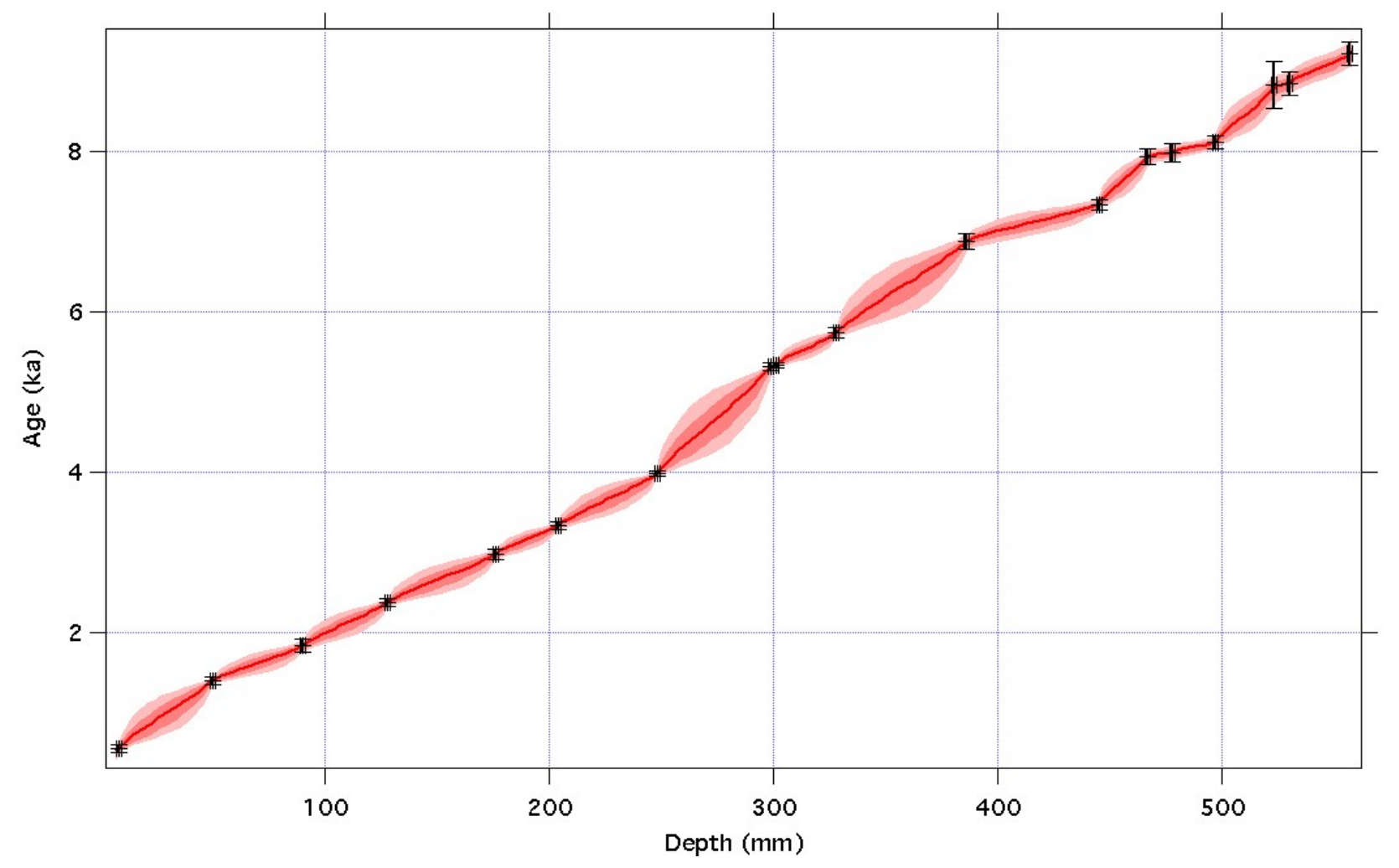

635 Figure 3 
636

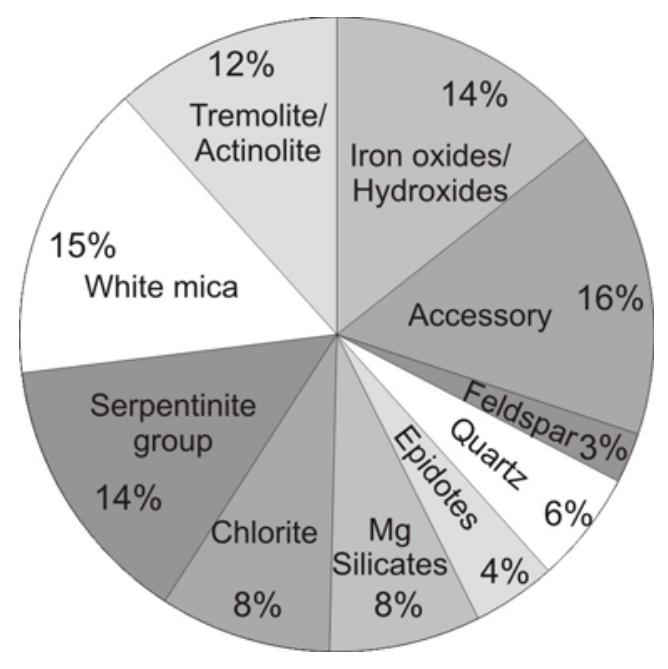

637 Figure 4

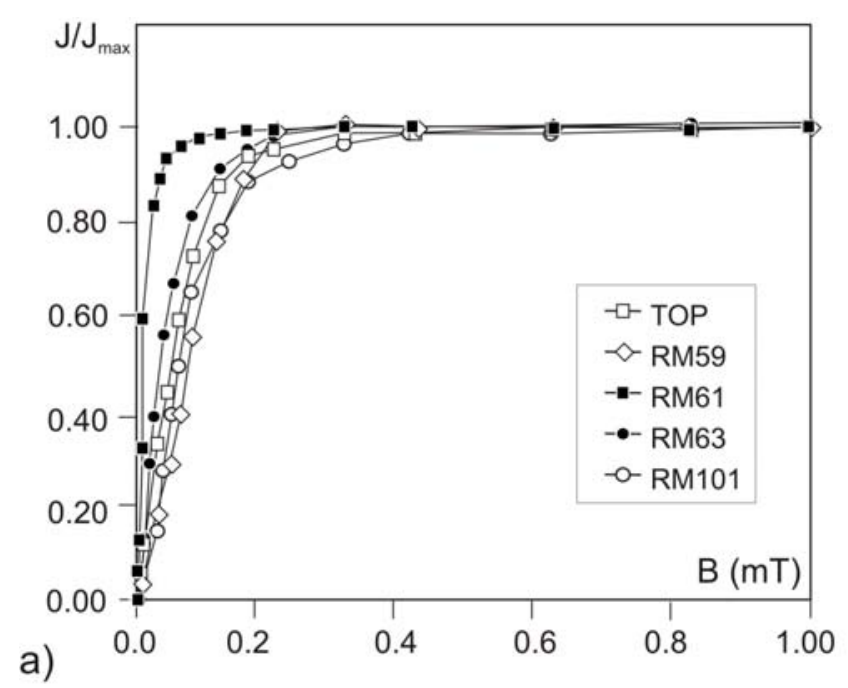

b)
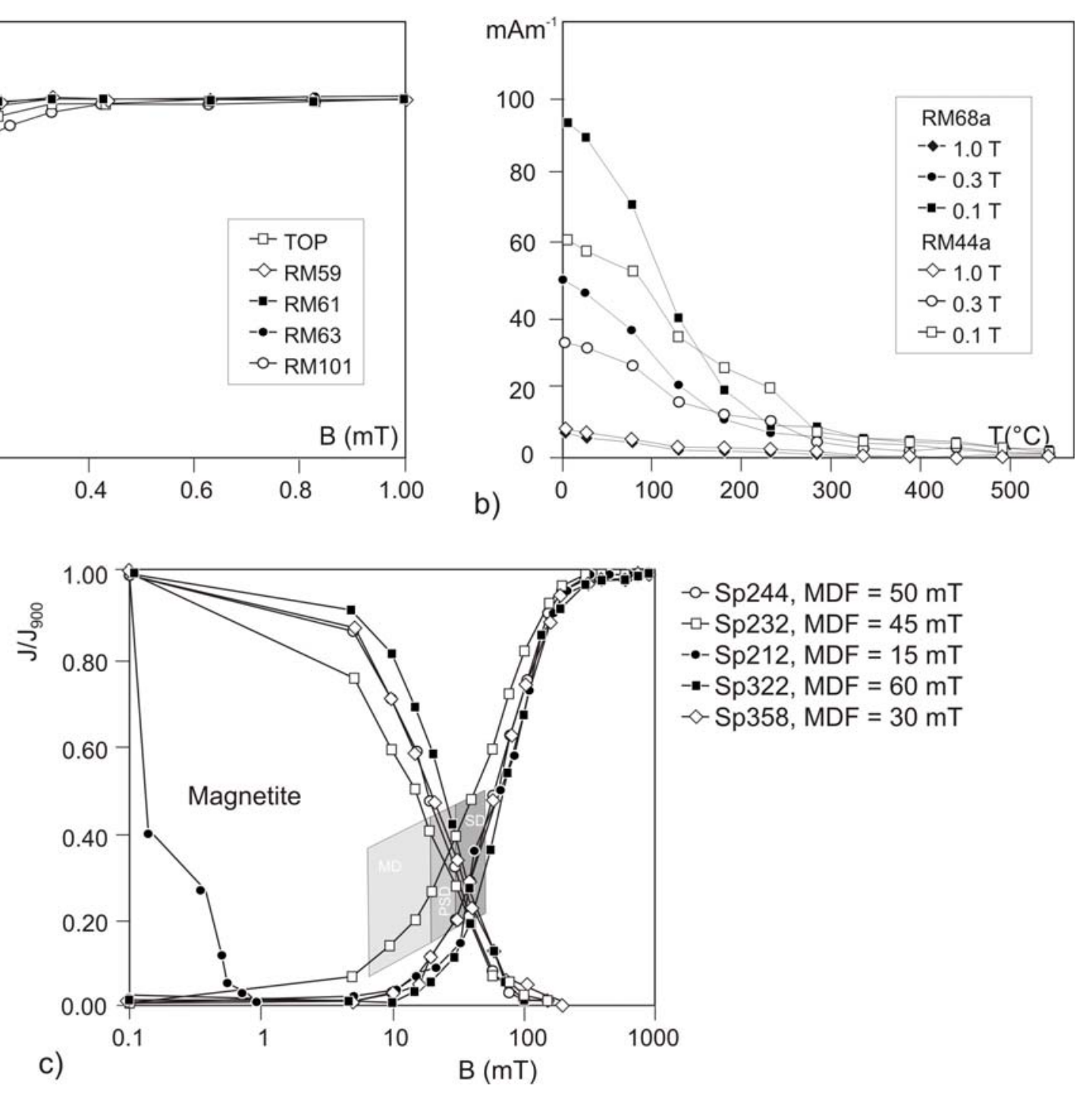

Figure 5 


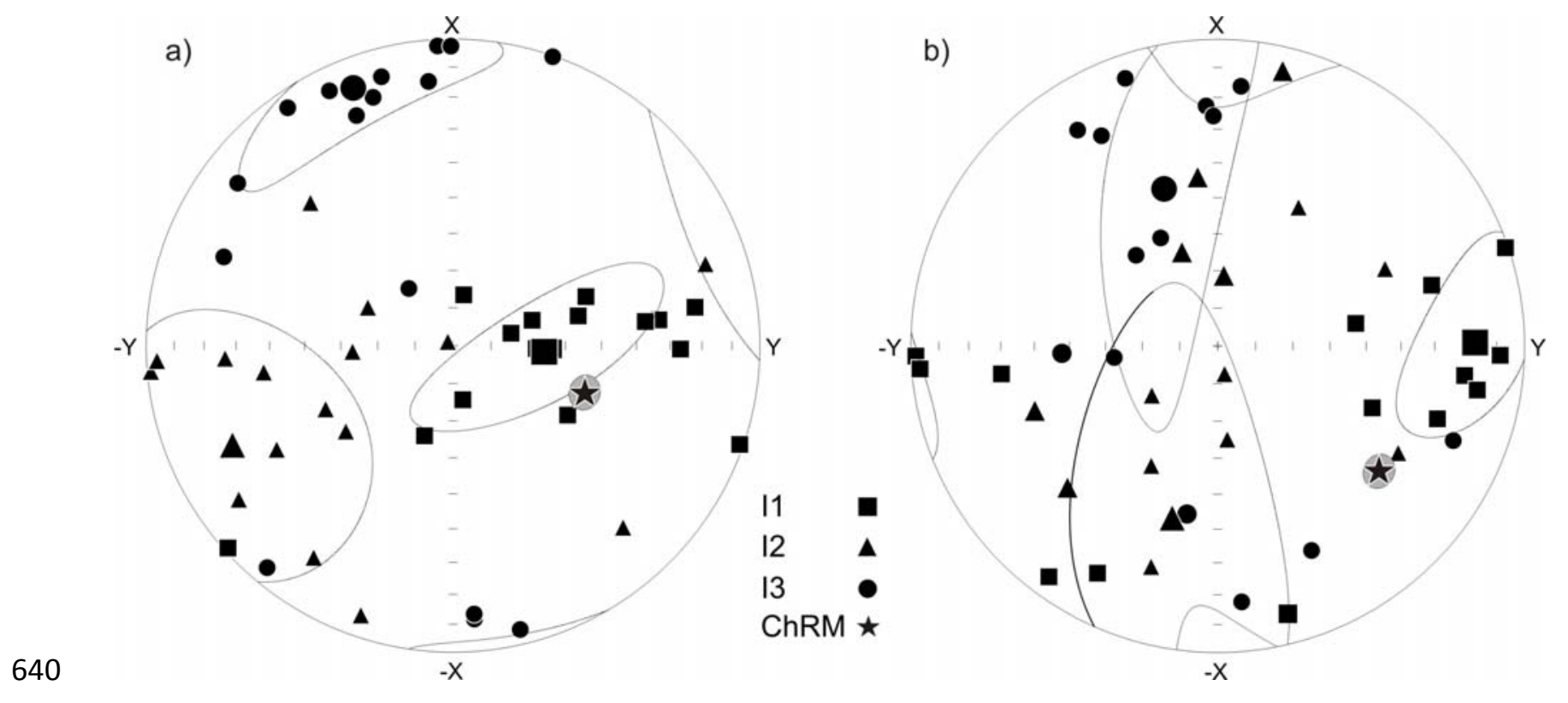

$641 \quad$ Figure 6 
a) specimen: RM7

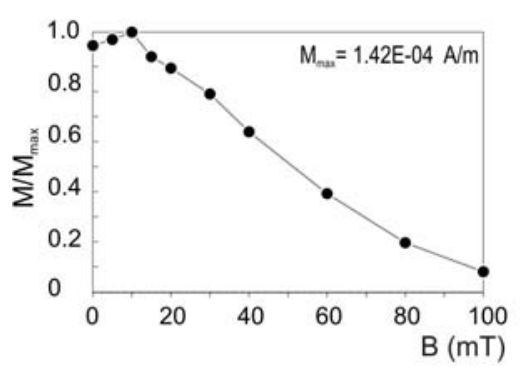

b) specimen: RM7a

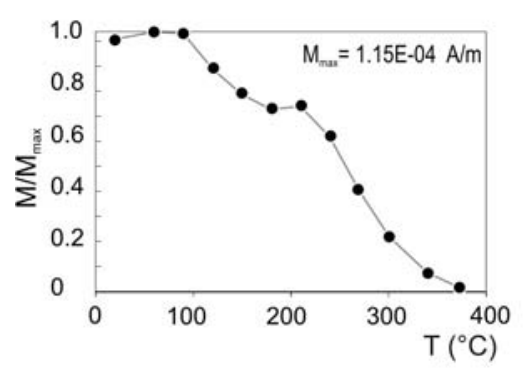

c) specimen: RM20

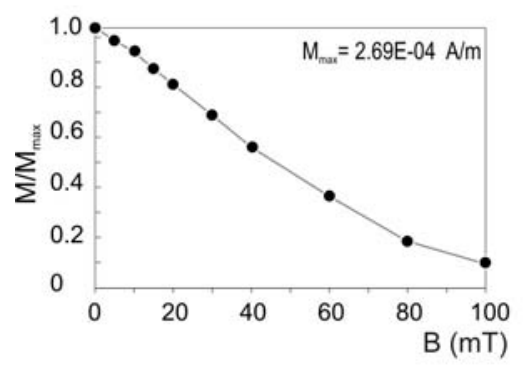

d) specimen: RM20a

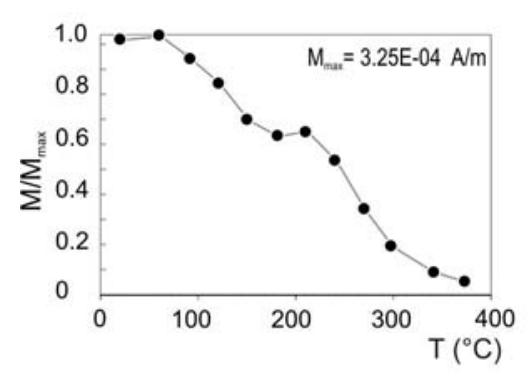

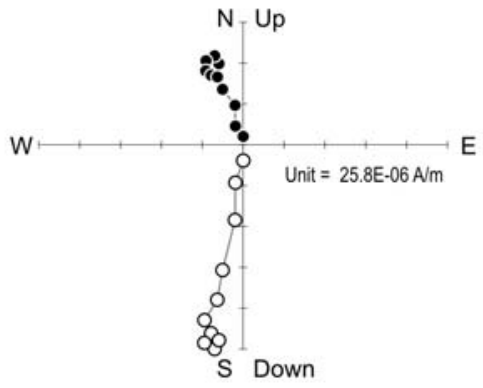
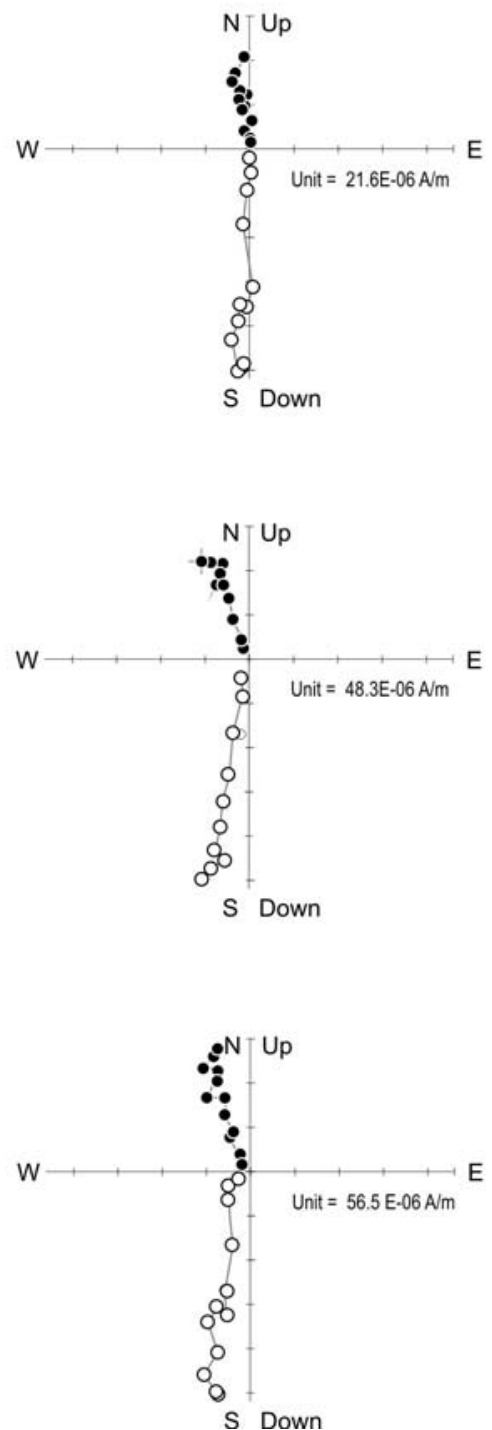


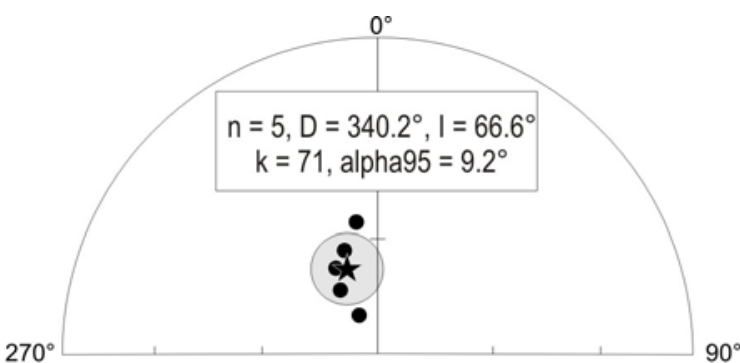

644

a) Af demagnetization

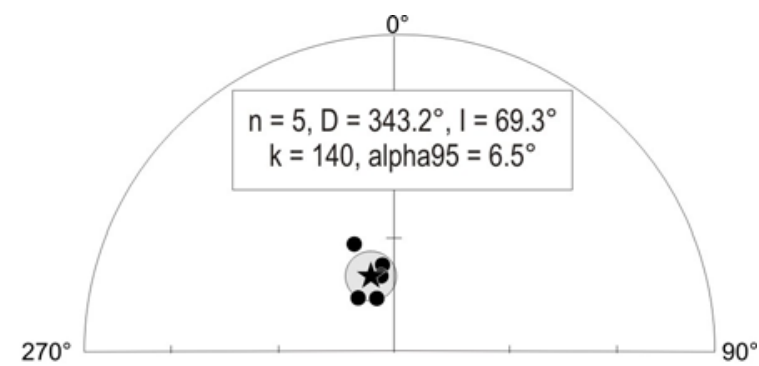

$645 \quad$ Figure 8

600.

500.0

400.0

300.0

200.0

100.0

0.0

RMD1

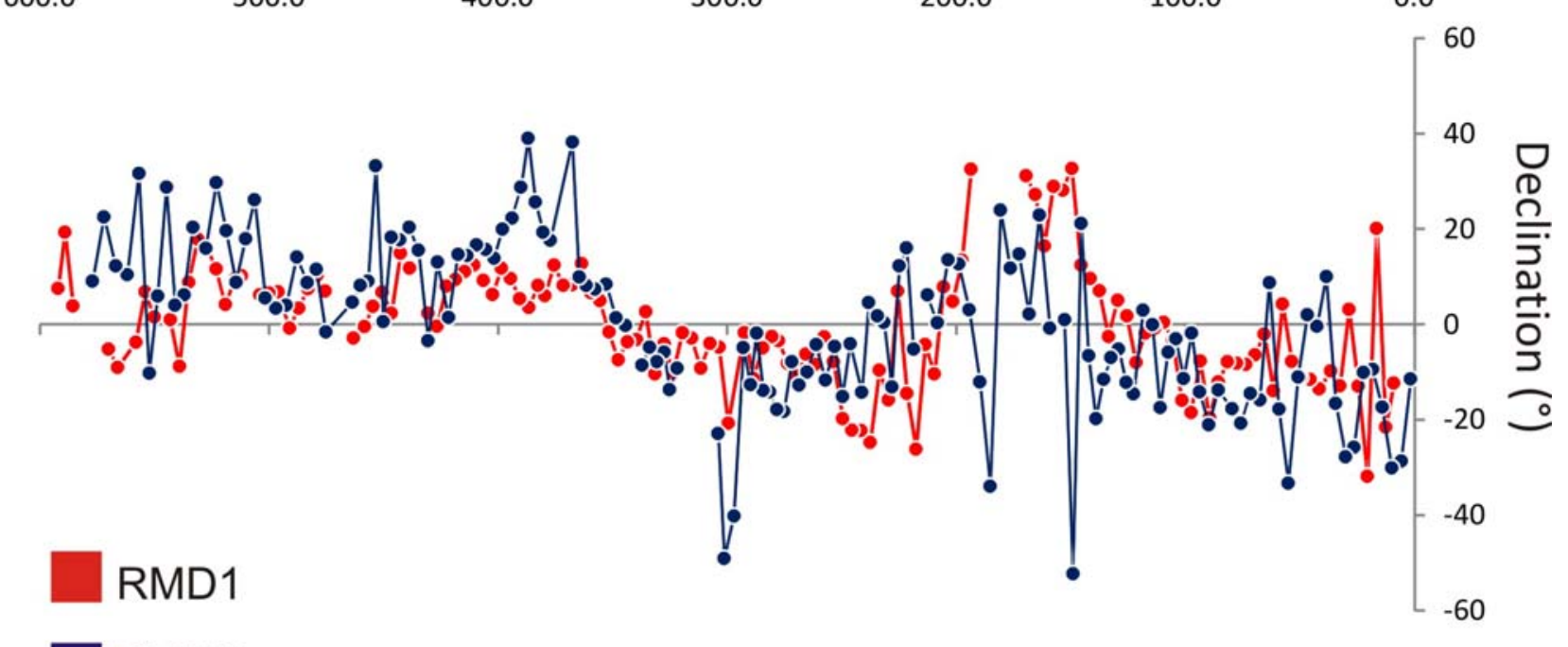

b) Thermal demagnetization

\section{$0^{\circ}$}

RMD8

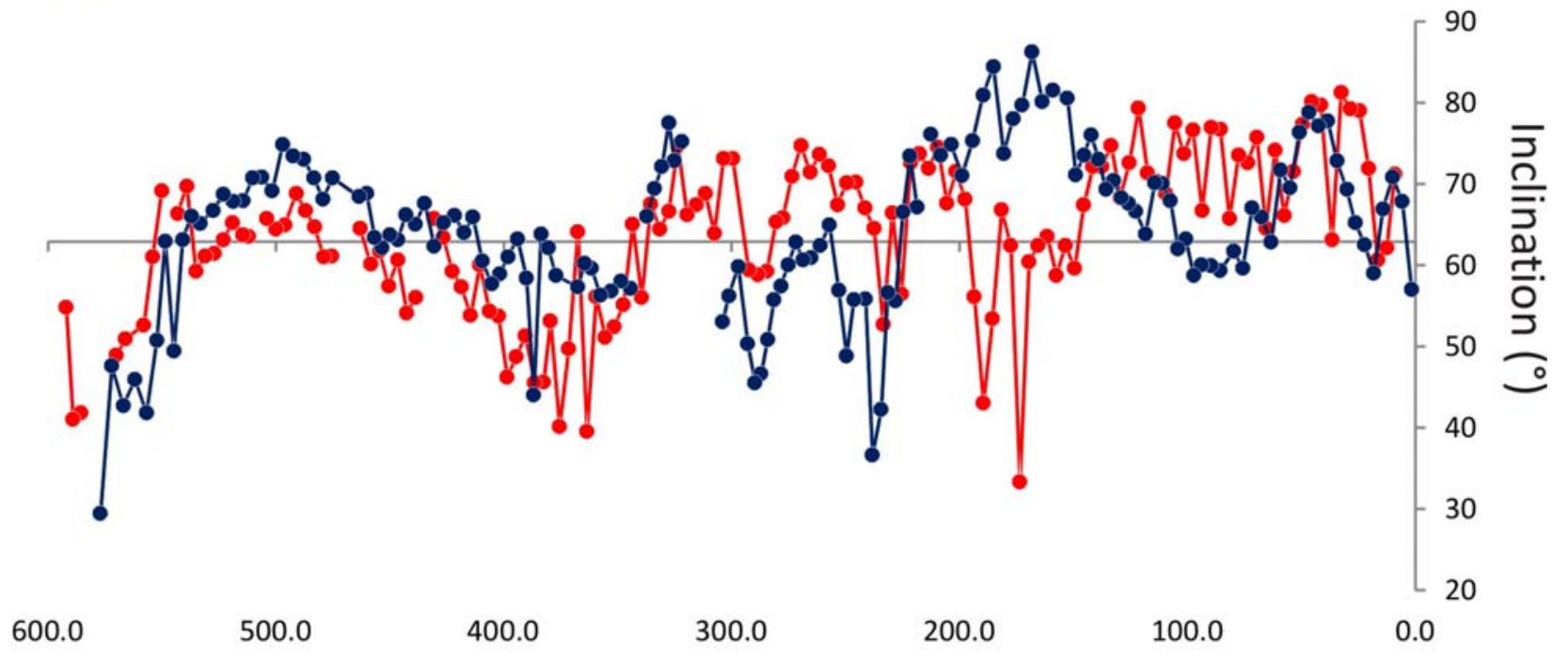

Figure 9

Depth ( $\mathrm{mm}$ from the core top) 


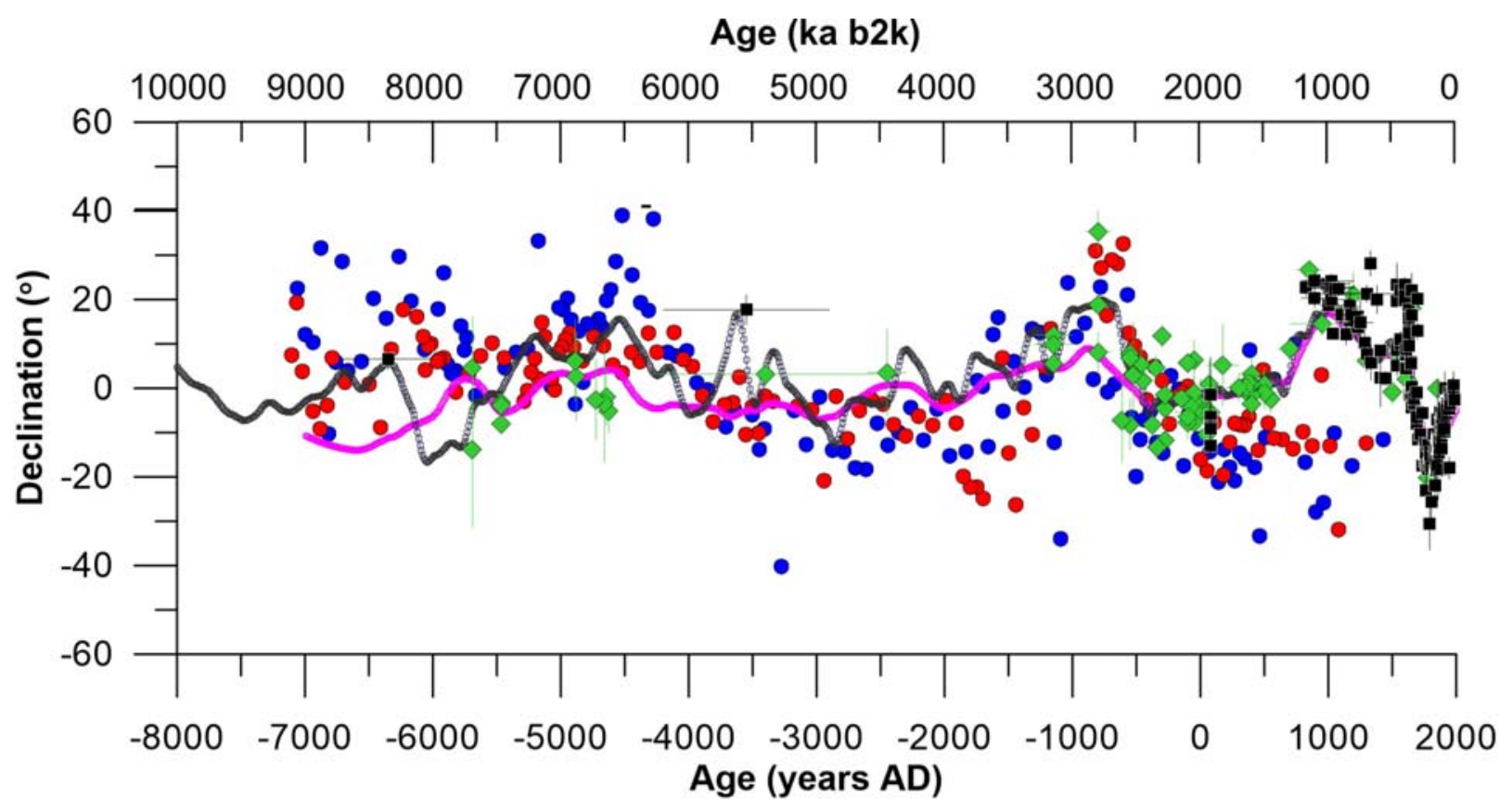

Age (ka b2k)

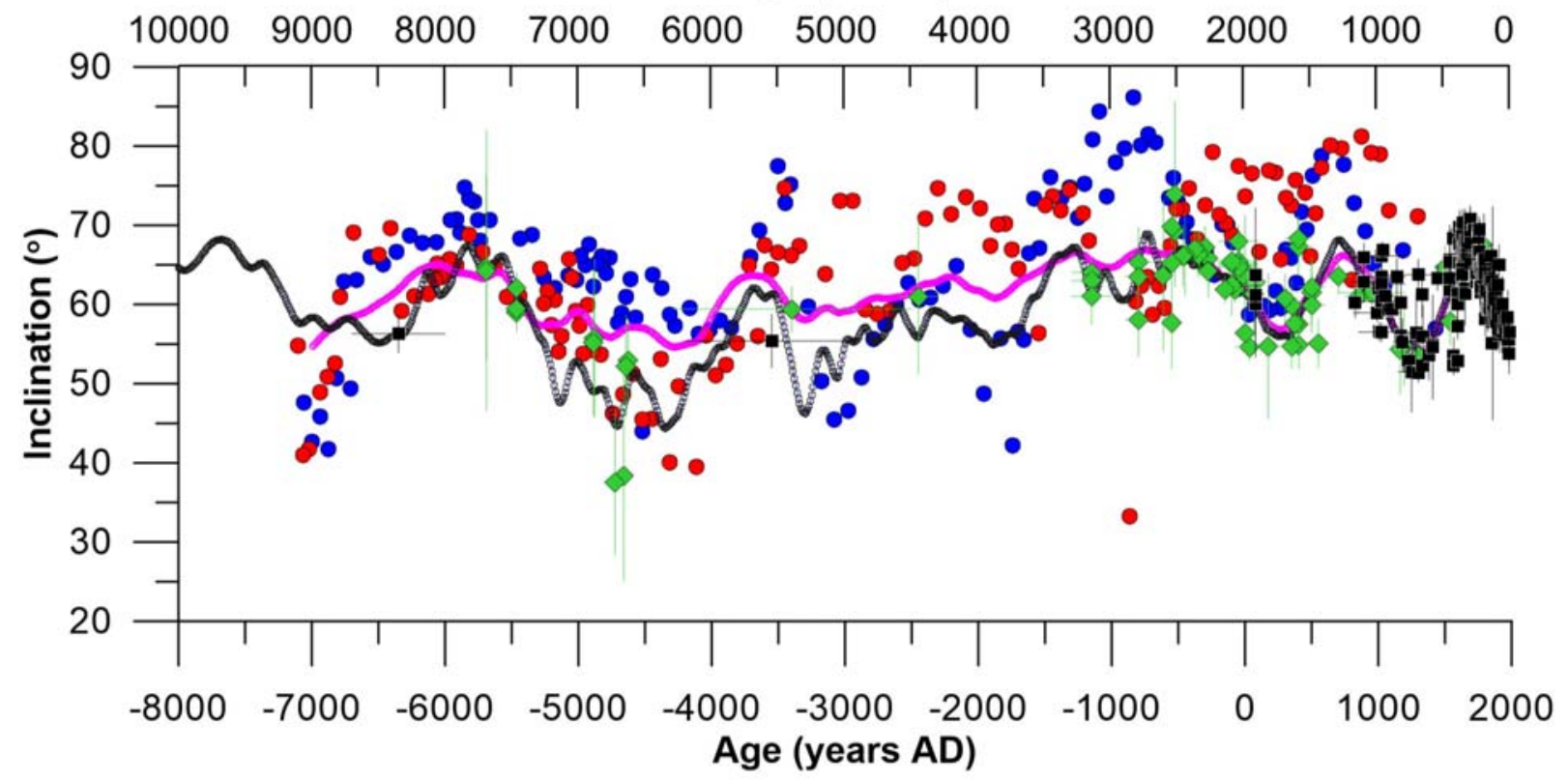

648

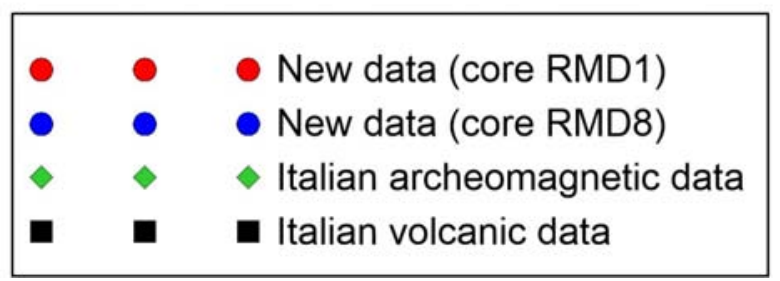

Figure 10 